\title{
PROGNOSIS OF TRANSPOSITION OF THE GREAT VESSELS WITH AND WITHOUT ATRIAL SEPTAL DEFECT
}

\author{
BY \\ REDA M. SHAHER \\ From the Cardiac Department, Guy's Hospital, London S.E.1
}

Received July 9, 1962

Among patients with complete transposition of the great vessels, Hanlon and Blalock (1948) correlated the age of survival with the associated anatomical defects. Their work was based mainly on 85 reported cases of transposition collected by Kato in 1930 to which they added 23 of their own and 15 others, reported since Kato's work by other authors. In the whole group of 123 cases, they found that the average age at death in those with complete transposition and an ASD was 1 year and 11 months, while in those with transposition and a VSD it was 4 years and 1 month: the combination of an ASD and a VSD gave an average survival time of 4 years and 9 months. These differences are discussed more fully later with Table IV.

In 1950, Blalock and Hanlon discussed the various other abnormalities that may provide a means of mixing between the systemic and pulmonary circulations in cases of transposition of the great vessels. Among these are patent ductus arteriosus and partial transposition of the great veins. They concluded that the combination of an ASD and a VSD gives the best prognosis for those having transposition of the great vessels and suggested that the surgical therapy for transposition might be to reproduce any of the defects previously mentioned. Three different types of surgical operation were suggested, but the one that is discussed here is the creation of an ASD and this is known as Blalock and Hanlon's operation.

The operation has been performed at many places with a reported mortality rate varying from 30-75 per cent (Blalock and Hanlon, 1950; Ash et al., 1959; Collins et al., 1959; and Ochsner et al., 1961). At Guy's Hospital this operation has been done on only two patients with transposition: the first was a boy aged 7 years who had also a single ventricle and the second a baby aged 3 months; and both died within 24 hours of operation.

Six patients with complete transposition of the great vessels who survived more than 20 years have been seen at Guy's Hospital and in all the diagnosis was confirmed at autopsy. All six had a large VSD and one only had an additional ASD measuring $5 \times 2 \mathrm{~mm}$., which was considered to have no hæmodynamic significance. Since very few patients with complete transposition of the great vessels live longer than 10 years, these findings were surprising when considered with the original observation of Hanlon and Blalock in 1948. Accordingly the life expectancy of cases of complete transposition of the great vessels was studied in relation to the associated septal defects.

Method and Subjects. Thirty-five cases of complete transposition of the great vessels, in each of which an anatomical diagnosis was established, were collected from two centres, 31 from Guy's Hospital and 4 from Southampton Chest Hospital. Cases of corrected transposition of the great vessels or of ordinary transposition combined with a single ventricle, tricuspid atresia, transposition of the tricuspid valve, isolated dextrocardia, or isolated lævocardia were excluded. The age of the patients ranged from 12 hours to 29 years. There were 20 male and 15 female patients. The anatomical diagnosis was confirmed at necropsy in 31 , by cardiac catheterization in 1 , by this and angiography in 1 , by catheterization and operation in 1 , and by all three methods in the remaining patient. 
Cases were classified into three groups according to the anatomy of the atrial and ventricular septa: (A) with only a VSD, (B) with an ASD and a VSD, and (C) with a closed ventricular septum. The average duration of life in each group was then determined.

\section{RESULTS}

Group A: 12 cases with a large VSD as the major associated defect (Table I). The diagnosis was confirmed at necropsy in all of these. All our cases had a large VSD as the only associated defect, except Case 4 who had a large VSD and a small ASD, $5 \times 2 \mathrm{~mm}$. in diameter, which was not considered to have any hæmodynamic significance. The six oldest patients already mentioned who lived

TABLE I

Group A: 12 CASES With a LARGE VSD

\begin{tabular}{|c|c|c|c|}
\hline No. & $\begin{array}{c}\text { Age } \\
\text { (years) }\end{array}$ & Sex & Necropsy findings \\
\hline $\begin{array}{c}1 \\
2 \\
3 \\
4 \\
5 \\
6 \\
7 \\
8^{*} \\
9 \\
10 \\
11 \\
12^{*}\end{array}$ & $\begin{array}{r}29 \\
26 \\
25 \\
25 \\
24 \\
21 \\
18 \\
12 \\
4 \\
1 \\
1 \\
4\end{array}$ & $\begin{array}{l}\mathbf{F} \\
\mathbf{F} \\
\mathbf{F} \\
\mathbf{M} \\
\mathbf{F} \\
\mathbf{M} \\
\mathbf{M} \\
\mathbf{M} \\
\mathbf{F} \\
\mathbf{M} \\
\mathbf{M}\end{array}$ & $\begin{array}{l}\text { VSD admitting } 2 \text { fingers } \\
\text { VSD } 3 \mathrm{~cm} \text {. in diameter } \\
\text { VSD } 4 \mathrm{~cm} \text {. (diam) and overlapping valvular PFO } \\
\text { Large VSD and ASD } 5 \times 2 \mathrm{~mm} \text {. } \\
\text { Large VSD } \\
\text { VSD } 2 \mathrm{~cm} \text {. in diameter } \\
\text { VSD } 2 \cdot 3 \mathrm{~cm} \text {. in diameter } \\
\text { Large VSD } \\
\text { VSD } 1 \mathrm{~cm} \text {. in diameter and small PFO } \\
\text { Large VSD } \\
\text { Large VSD } \\
\text { Large VSD }\end{array}$ \\
\hline \multicolumn{4}{|c|}{$\begin{array}{ll}\text { VSD }=\text { Ventricular septal defect } & \text { PDA = Patent ductus arteriosus } \\
\text { ASD = Atrial septal defect } & \text { PAPVD = Partial anomalous pulmonary } \\
\text { PFO = Patent foramen ovale } & \text { venous drainage } \\
\text { *Southampton cases } & \end{array}$} \\
\hline
\end{tabular}

over 20 years and two more who lived over 10 years were in this group. Case 2 died at the age of 26 years following appendicectomy. Case 5 died at the age of 24 years in a road accident. Case 1 died at the age of 29 years and Case 4 at the age of 25 years, each of their deaths being a result of an operation to relieve their pulmonary stenosis. Cases 3 and 6 died at 25 and 21 years as a result of a cerebral abscess and heart failure respectively. The age limit varied from 3 months to 29 years with an average of 15 years and 5 months.

Group B: 6 cases with an ASD and a VSD (Table II). The diagnosis was confirmed post mortem in 2 cases and by cardiac catheterization sometimes associated with angiography or operation in the remaining 4 cases. Cases 14, 15, and 18 are still alive but extremely cyanosed and disabled. Cases 14 and 16 have been operated on for relief of their pulmonary stenosis. The ages of the patients in this group varied from 5 to 8 years with an average of 7 years and 2 months.

TABLE II

Group B: 6 CASES WITH AN ASD AND A VSD

\begin{tabular}{|c|c|c|c|}
\hline No. & $\begin{array}{c}\text { Age } \\
\text { (years) }\end{array}$ & Sex & Source and type of information \\
\hline $\begin{array}{l}13 \\
14 \\
15 \\
16 \\
17 \\
18\end{array}$ & $\begin{array}{l}8 \\
8 \\
8 \\
7+ \\
7 \\
5+\end{array}$ & $\begin{array}{l}\mathbf{M} \\
\mathbf{F} \\
\mathbf{F} \\
\mathbf{M} \\
\mathbf{F} \\
\mathbf{F}\end{array}$ & $\begin{array}{l}\text { P.M. VSD and ASD } \\
\text { Cardiac catheterization and operation } \\
\text { Cardiac catheterization and angiography } \\
\text { Catheterization, angiography, and operation } \\
\text { Catheterization and operation } \\
\text { Operation and P.M. }\end{array}$ \\
\hline
\end{tabular}


Group C: 17 cases with a closed ventricular septum (Table III). The diagnosis was confirmed post mortem in 16 patients and by cardiac catheterization in the 1 still living. Atrial septal defect or patent foramen ovale together with a patent ductus arteriosus occurred in 9 cases, ASD alone in 3 , patent foramen ovale in 2 , patent ductus arteriosus in 1 , and patent foramen ovale together with partial anomalous pulmonary venous drainage in 1 case. Case 30 did not have any associated defects at all and yet survived for two weeks. 14 cases died during the first year of life, the majority of them being less than 3 months old. One patient is still living at 16 years. The average age of survival of the whole group was 22 months.

TABLE III

Group C: 17 Cases with Closed Ventricular Septum

\begin{tabular}{c|c|c|ll}
\hline No. & Age & Sex & \multicolumn{2}{|c}{ Source and type of information } \\
\hline 19 & 16 yr & F & \multicolumn{2}{|c}{ Cardiac catheterization } \\
20 & 10 yr & F & P.M. & PFO \\
21 & 2 yr & F & P.M. & PFO+PAPVD \\
22 & 5 mo. & M & P.M. & ASD \\
23 & 3 mo. & M & P.M. & ASD+PDA \\
24 & 3 mo. & M & P.M. & ASD+PDA \\
25 & 3 mo. & M & P.M. & ASD+PDA \\
26 & 2 mo. & M & P.M. & ASD \\
27 & 6 wk & F & P.M. & PFO+PDA \\
28 & 6 wk & F & P.M. & PFO+PDA \\
29 & 4 wk & M & P.M. & PDA \\
30 & 2 wk & M & P.M. & No associated defects \\
31 & 1 wk & M & P.M. & PFO \\
32 & 1 wk & M & P.M. & ASD+PDA \\
33 & 2 days & M & P.M. & PFO+PDA \\
34 & 2 days & F & P.M. & PFO+PDA \\
35 & 1 day & M & P.M. & PFO+PDA \\
\hline
\end{tabular}

Abbreviations as in Table I

\section{DisCUSSION}

It appears from our figures that patients with transposition of the great vessels and a closed ventricular septum have the worst prognosis, as the majority of them die before they are 3 months old. Occasionally, however, the isolated occurrence of a large atrial septal defect or a wide patent foramen ovale may allow an adequate exchange of blood between the two circuits and the patient may live much longer. Cases 19 and 20 fulfilled these criteria: Case 19 is still living at 16 years and Case 20 lived until 10 years and 7 months of age. The case reported by Pung, Gottstein, and Hirsch (1955), which died at 18 years, had a closed ventricular septum and a large widely patent foramen ovale.

The best prognosis, however, occurred in those patients with a large ventricular septal defect as the only associated defect. The average life expectancy of our 12 patients was 15 years and 5 months. The additional occurrence of an atrial septal defect reduced the life expectancy, for in 6 patients in whom an ASD and a VSD occurred, it was 7 years and 2 months, which is less than one half.

Of the 5 undoubted cases of complete transposition of the great vessels reported by Campbell and Suzman (1951), Cases 3 and 4 exceeded 10 years and neither had a L-R shunt at atrial level. In the group of 50 cases of complete transposition of the great vessels published by Noonan et al. (1960), only two exceeded the age of 10 years (Cases 1 and 6, group 2B) and in neither was there any evidence of any form of blood shunting at atrial level. The case reported by Messeloff and Weaver (1951) that survived until the age of 38 years had a normal valvular patency of the foramen ovale but no ASD. These reports support our figures which indicate that patients with transposition of the great vessels and a large ventricular septal defect as the only associated abnormality have the 
best prognosis. It seems therefore that the heart in transposition tolerates one bidirectional shunt at ventricular level better than two unidirectional shunts or two bidirectional shunts at two levels.

Analysis of Other Reported Cases. Hanlon and Blalock (1948) concluded from 123 cases that the combination of an atrial septal defect and a ventricular septal defect in a patient with complete transposition of the great vessels would give the best prognosis (Table IV). They pointed out that the inclusion of two cases, aged 19 and 56 years, gave an unduly favourable character to the average survival time for the group with combined defects: without this pair the average life span of the group would be less than one year.

TABLE IV

Prognosis on Data of Hanlon and Blalock (1948)

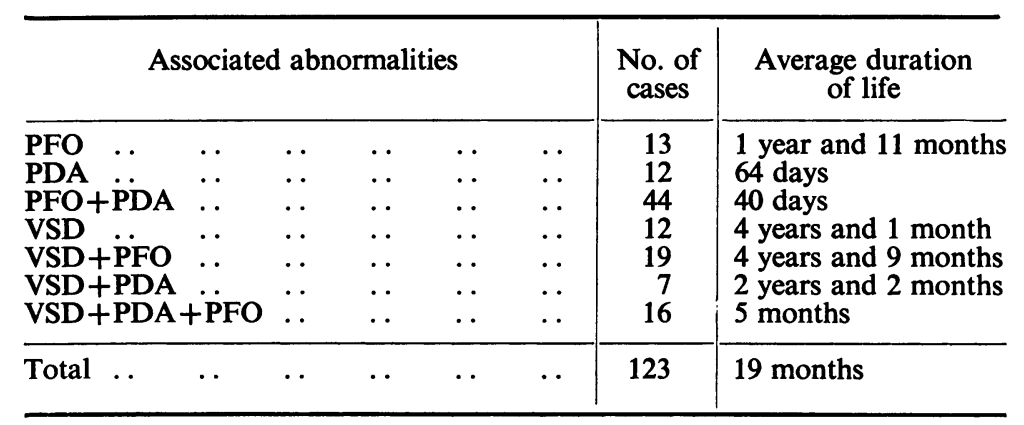

VSD and PDA, as in Table $I$

$\mathrm{PFO}=$ Any form of interatrial communication

In Kato's original paper (1930), the patient, aged 19 years, was described as having a patent foramen ovale, an open ventricular septum, and a contracted pulmonary artery, and the patient aged 56 years was described as having a partially patent foramen ovale, a ventricular septal defect, and a closed ductus arteriosus. Moreover Kato used the words patent foramen ovale to describe any form of interatrial communication whether it was an atrial septal defect or a patent foramen ovale. Hanlon and Blalock accepted Kato's expression of patent foramen ovale, as meaning a hæmodynamically significant atrial septal defect, and on this assumption they concluded that the combination of an atrial septal defect and a ventricular septal defect in a patient with transposition gives the best prognosis. The exact type of the interatrial communication cannot be determined in these two cases, though the fact that Kato used the expression of partially open foramen ovale to describe the case that survived until the age of 56 years, makes it very likely that it was a patent foramen ovale proper rather than an atrial septal defect. The inclusion of this case in the group with an ASD and a VSD is probably inappropriate.

It would also be expected that, if additional shunts improved prognosis, the association of a PDA and a VSD would give a better prognosis than the latter alone, or that the association of a PDA, VSD, and ASD would give an even better prognosis than ASD and VSD alone. This is not shown in their figures, for the average life span of the group with a VSD and a PDA was two years and two months and of the group with a VSD, ASD, and PDA was five months, compared with four years and one month in the group with a ventricular septal defect alone.

Lillehei and Varco(1953) repeated the statement of Hanlon and Blalock (1948), that the combination of an ASD and a VSD gives the best prognosis in transposition of the great vessels. Yet if one reviews their cases one finds that their three oldest patients had only a ventricular septal defect. Two of them (Cases 14 and 29) were aged $4 \frac{1}{2}$ years and the third (Case 28) was aged $6 \frac{1}{2}$ years. Furthermore if their 29 cases are classified into five groups according to the associated abnormalities (Table V), one finds that the life expectancy of their group with a VSD as the major hæmodynamic abnormality is almost double that of the group with a VSD and an ASD. 
TABLE V

Prognosis Based on Data of Lillehei and Varco (1953)

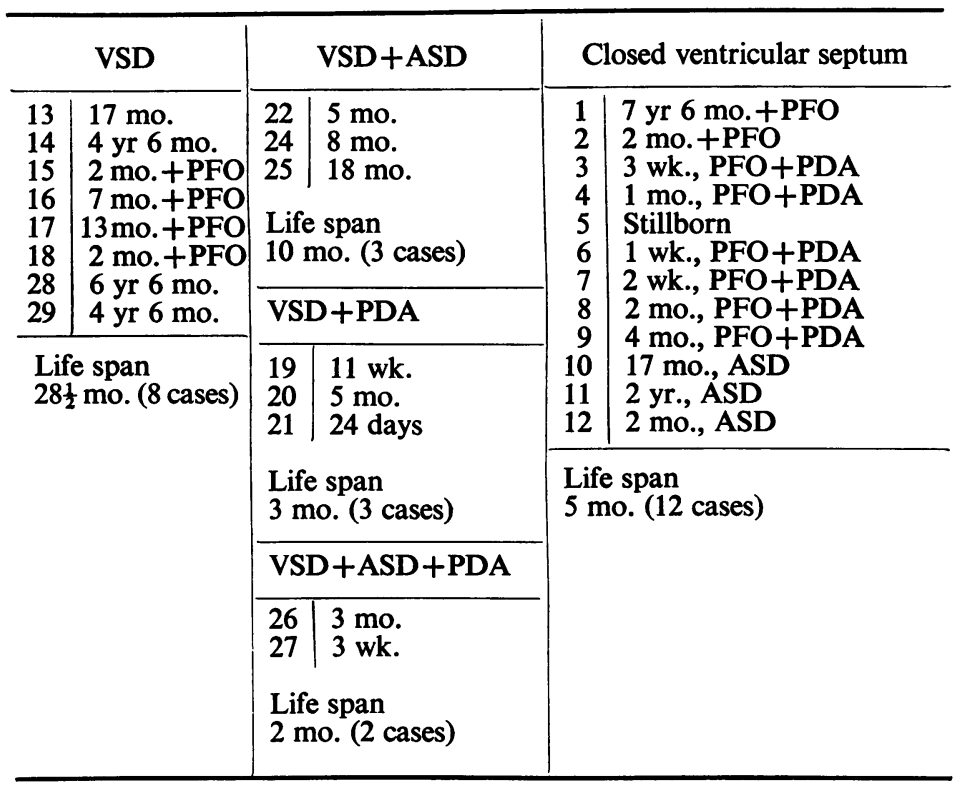

Abbreviations as in Table I

Case 23 had a single ventricle and was excluded

Blalock and Hanlon (1950) treated 12 patients with complete transposition of the great vessels by creating an atrial septal defect: only 3 survived and appeared to have benefited by the operation; and the remaining 9 died, most of them less than 24 hours after the operation. They reported a disquieting aspect of the surgical therapy of transposition, that a number of survivors were only moderately improved, and that the arterial saturation generally remained below 75 per cent and in some instances the red cell count increased after operation. Ash et al. (1959) reported their results of operation on 17 patients with complete transposition of the great vessels: 4 of 10, in whom a defect of the atrial septum was created, survived with improvement. Collins et al. (1959) reported their results on 17 patients with transposition of the great vessels operated upon between 1 week and 7 months of age, an atrial septal defect was created in 13 with 9 survivors. Ochsner et al. (1961) reported the results on $\mathbf{4 5}$ patients with transposition of the creation of an atrial septal defect: the majority of them were under 1 year of age and the overall mortality rate was 33 per cent.

The Hamodynamics of the Circulation after Creation of an ASD. It is relevant to consider why the addition of an atrial septal defect appears to diminish the life expectancy of patients with transposition and a ventricular septal defect. In complete transposition of the vessels, the pulmonary and systemic circulations would be completely separate if there were no associated defects. The volume of blood exchanged between the two circulations must be the same in each direction, i.e. the R-L shunt equals the L-R shunt.

Any shunt into an atrium will increase the work of this atrium and the corresponding ventricle. This may be more understandable from the following hypothetical figures. Let us assume in a case of complete transposition, that the pulmonary and systemic flows are $121 . / \mathrm{min}$. and $61 . / \mathrm{min}$. respectively and that the shunt in either direction is $31 . / \mathrm{min}$. If only a ventricular septal defect is present, a bidirectional shunt will occur at ventricular level. The output of the left atrium will be $121 . / \mathrm{min}$. and that of the right atrium $61 . / \mathrm{min}$. Each ventricle will lose $31 . / \mathrm{min}$. but will also gain the same amount, so that the output of the left ventricle will eventually be $121 . / \mathrm{min}$. and that of the right ventricle 61 ./min. (Fig. 1). 


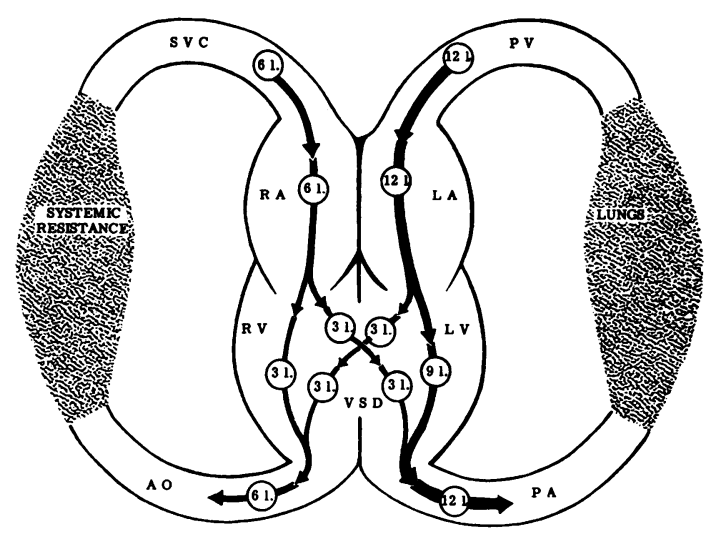

A

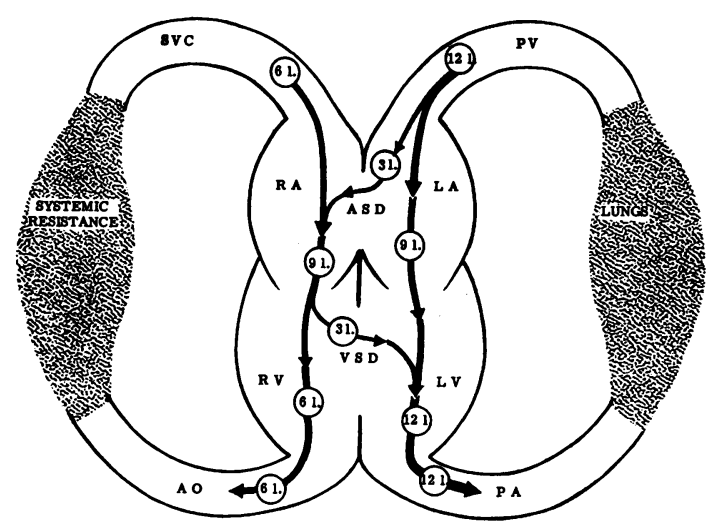

B

FIG. 1. Diagrammatic scheme of the shunts in ventricular septal defects; (A) without, and (B) with the addition of an atrial septal defect.

The hæmodynamics of complete transposition of the great vessels are not completely understood, but if there is also an atrial septal defect present and the pulmonary vascular resistance is lower than the systemic resistance, a unidirectional $\mathbf{R}-\mathbf{L}$ shunt may occur at ventricular level and an equal L-R shunt may occur at atrial level (Wood, 1956). The output of the left atrium will remain $121 . / \mathrm{min}$., $31 . / \mathrm{min}$. being shunted to the right atrium and $91 . / \mathrm{min}$. passing through the mitral valve. The right atrium is now receiving $31 . / \mathrm{min}$. from the left besides the systemic venous return of $61 . / \mathrm{min}$., which brings its total output up to $91 . / \mathrm{min}$. The output of the right ventricle is also $91 . / \mathrm{min}$., of which $31 . / \mathrm{min}$. is shunted to the left ventricle through the ventricular septal defect and $61 . / \mathrm{min}$. is passed to the aorta. The output of the left ventricle remains $12 \mathrm{l} . / \mathrm{min}$., this being composed of $9 \mathrm{l}$./min. from the left atrium and 31 ./min. from the right ventricle (Fig. 2).

In other words, with the same amount of bidirectional shunt, the creation of an atrial septal defect has increased the load handled by the right side of the heart without reducing that handled by the left. Taking into consideration the limited reserves of the coronary circulation in complete transposition of the great vessels (Astley and Parsons, 1952; Shaher, 1963), the shortening of the life span in cases of transposition with a VSD when an ASD is created may be explained by the following reasons. (1) The ASD increases the work of the right side of the heart without increasing the amount of the blood exchanged between the two circulations, as shown in this hypothetical case. (2) The ASD may increase the magnitude of the bidirectional shunt and may improve the arterial $\mathrm{O}_{2}$ saturation, but the extra load imposed on the right side of the heart outweighs the benefit so obtained.

Indications for Blalock and Hanlon's Operation. With the development of satisfactory surgical techniques for the complete correction of transposition of the great vessels, e.g. transplantation of the atria (Senning, 1959) or transplantation of the arteries (Idriss et al., 1961), operations designed for the palliative therapy of this condition should only be used in special circumstances. Our figures suggest that the Blalock and Hanlon operation is not likely to benefit patients in whom a large VSD is demonstrated but may serve as palliative therapy for those with a closed ventricular septum in whom a small ASD or PFO is thought to be present. It is unfortunate that detailed anatomy of the ventricular septum in cases subjected to this operation was not described by Blalock and Hanlon (1950), Ash et al. (1959), Collins et al. (1959), and Ochsner et al. (1961).

Reviewing the hæmodynamics of 19 cases of complete transposition of the great vessels with closed ventricular septum that were reported by Fowler and Ordway (1952), Lenkei, Swan, and DuShane (1959), Noonan et al. (1960), and Idriss et al. (1961), and the case investigated in this hospital, one finds that those who have survived the first $2 \frac{1}{2}$ years of life generally had a brachial artery saturation of more than 60 per cent. The demonstration therefore of a $L-R$ shunt at atrial level which is responsible for a brachial artery saturation of more than 65 per cent, in a case of trans- 
position with a closed ventricular septum, generally indicates the presence of a large atrial communication, and thus contraindicates Blalock and Hanlon's operation.

The diagnosis of a closed ventricular septum in transposition is mainly made by cardiac catheterization: the demonstration of two ventricles with two different pressures is suggestive. For reasons that will not be discussed here, the L.V. pressure is generally lower than the R.V. pressure. In the 12 cases reported by Noonan et al. (1960), the L.V. pressure was lower than the R.V. pressure in 9, the same in 1 , and higher in the remaining 2 . In the case studied in this hospital the R.V. pressure was $80 /-2$ and the L.V. pressure was $50 /-1 \mathrm{~mm}$. Hg. The R.V. pressure was higher than the L.V. pressure in the two cases of Fowler and Ordway (1952), the two of Lenkei et al. (1959), and the two of Idriss et al. (1961). Dye curves obtained from the right ventricle will show rapid appearance and rapid disappearance, whereas those from the left ventricle will show slower appearance and prolonged disappearance (Lenkei et al., 1959).

\section{SUMMARY}

Hanlon and Blalock (1948), correlating the age of survival with the associated anatomical defects, in subjects having complete transposition of the great vessels, found that those with an ASD had an average survival time of 23 months, while those with a VSD had one of 49 months. The combination of a VSD and an ASD gave an average age of survival of 57 months in 19 cases. On this basis Blalock and Hanlon (1950) suggested the creation of an ASD as a palliative treatment for patients with complete transposition of the great vessels.

Thirty-five patients have been seen at Guy's Hospital and Southampton Chest Hospital with complete transposition of the great vessels in whom an anatomical diagnosis had been established. They have been divided into three groups, according to the nature of the septal defects, and the ages of survival analysed.

It appears that in patients with transposition and a VSD, the additional occurrence of an ASD reduces the life expectancy. Reviewing the cases analysed by Blalock and Hanlon shows that their conclusions rested upon the probably inappropriate inclusion of two cases with long survival in the group with an ASD and a VSD.

The creation of an atrial septal defect, in cases of complete transposition with a ventricular septal defect, is thought to increase the work of the heart out of proportion to the benefit derived from the increase in the magnitude of the bidirectional shunt. It is suggested that the proper indication for this operation is in a patient who has transposition with a closed ventricular septum and only a small atrial septal defect or a small patent foramen ovale.

I am indebted to Dr. C. G. Baker and D. C. Deuchar for helpful criticism of the manuscript; to them and Dr. P. R. Evans, R. C. MacKeith, and M. Joseph for permission to study their patients; and to Sir Russell Brock and Mr D. Ross for their reports of findings at operation. I am grateful to Dr. R. V. Gibson for allowing me to study his cases at Southampton Chest Hospital, to him and Dr. A. M. Johnson for their continuous encouragement and help, and also to Professor G. Payling Wright for allowing me to study the records of the Pathology Department. I wish to thank Miss D. Healy of the Cardiac Department, Guy's Hospital for her assistance during the preparation of this work.

\section{REFERENCES}

Ash, R., Johnson, J., Koop, C. E., Friedman, S., and Rashkind, W. (1959). Cardiovascular surgery in a children's hospital; II cyanotic lesions. A review of 193 operations. J. Pediat., 54, 348.

Astley, R., and Parsons, C. (1952). Complete transposition of the great vessels. Brit. Heart J., 14, 13.

Blalock, A., and Hanlon, C. R. (1950). The surgical treatment of complete transposition of the aorta and the pulmonary artery. Surg. Gynec. Obstet., 90, 1.

Campbell, M., and Suzman, S. (1951). Transposition of the aorta and pulmonary artery. Circulation, 4, 329.

Collins, H. A., Harberg, F. J., Soltero, L. R., McNamara, D. G., and Cooley, D. A. (1959). Cardiac surgery in the newborn: experience with 120 patients under one year of age. Surgery, 45, 506.

Fowler, R. E. L., and Ordway, N. K. (1952). Circulatory dynamics in complete transposition of the great vessels: physiologic considerations with report of four cases. Amer. J. Dis. Child, 83, 414.

Hanlon, C. R., and Blalock, A. (1948). Complete transposition of the aorta and the pulmonary artery: experimental observations on venous shunts as corrective procedures. Ann. Surg., 127, 385.

Idriss, F. S., Goldstein, I. R., Grana, L., French, D., and Potts, W. J. (1961). A new technic for complete correction of transposition of the great vessels. Circulation, 24,5 . 
Kato, K. (1930). Congenital transposition of cardiac vessels: a clinical and pathologic study. Amer. J. Dis. Child., $39,363$.

Lenkei, S. C., Swan, H. J. C., and DuShane, J. W. (1959). Transposition of the great vessels with atrial septal defect: a hemodynamic study in two cases. Circulation, 20, 842 .

Lillehei, C. W., and Varco, R. L. (1953). Certain physiologic, pathologic and surgical features of complete transposition of the great vessels. Surgery, 34, 376.

Messeloff, C. R., and Weaver, J. C. (1951). A case of transposition of the large vessels in an adult who lived to the age of 38 years. Amer. Heart J., 42, 467.

Noonan, J. A., Nadas, A. S., Rudolph, A. M., and Harris, G. B. C. (1960). Transposition of the great arteries: a correlation of clinical, physiologic and autopsy data. New Engl. J. Med., 263, 592.

Ochsner, J. L., Cooley, D. A., Harris, L. C., and McNamara, D. G. (1961). Treatment of complete transposition of the great vessels with the Blalock-Hanlon operation. Circulation, 24, 51.

Pung, S., Gottstein, W. K., and Hirsch, E. F. (1955). Complete transposition of great vessels in a male aged 18 years. Amer. J. Med., 18, 155.

Senning, $\AA$. (1959). Surgical correction of transposition of the great vessels. Surgery, 45, 967.

Shaher, R. M. (1963). The coronary circulation in complete transposition of the great vessels. Brit. Heart J., in the press.

Wood, P. (1956). Diseases of the Heart and Circulation, 2nd ed. Eyre and Spottiswoode, London. 